\title{
BMJ Open Are there long-term benefits of experiential, interprofessional education for non-specialists on clinical behaviours and outcomes in diabetes care? A cohort study
}

\author{
Daniel Ching, ${ }^{1}$ Denise Forte, ${ }^{1}$ Elizabeth Aitchison, ${ }^{1}$ Kenneth Earle ${ }^{1,2}$
}

To cite: Ching D, Forte D, Aitchison $\mathrm{E}$, et al. Are there long-term benefits of experiential, interprofessional education for non-specialists on clinical behaviours and outcomes in diabetes care? A cohort study. BMJ Open 2016;6:e009083.

doi:10.1136/bmjopen-2015009083

- Prepublication history for this paper is available online. To view these files please visit the journal online (http://dx.doi.org/10.1136/ bmjopen-2015-009083).

Received 22 June 2015 Revised 28 September 2015 Accepted 16 October 2015

CrossMark

\begin{abstract}
${ }^{1}$ St George's University of London, London, UK

${ }^{2}$ Thomas Addison Unit, St George's Healthcare NHS Trust, London, UK
\end{abstract}

Correspondence to Dr Kenneth Earle; kearle@sgul.ac.uk

\section{ABSTRACT}

Objectives: Our aim was to assess the impact of an educational initiative for non-specialist, healthcare professionals in the community on the process and quality measures of diabetes care delivered, and changes in their learning experiences and clinical management behaviour in the short and long term. Setting: Single locality of 26 primary care practices associated with one secondary centre.

Participants: General practitioners and practice nurses managing 4167 patients with diabetes.

Intervention: A rolling 10-week, experiential, interprofessional education programme delivered to 57 practitioners and observations in practice.

Primary and secondary outcome measures:

Primary outcomes were changes in the proportion of patients receiving foot care, urine albumin:creatinine ratio assessments and achieving National Quality Outcome Framework targets for blood pressure $(<145 / 80 \mathrm{~mm} \mathrm{Hg})$, glycated haemoglobin (HbA1c; > $86 \mathrm{mmol} / \mathrm{mol}(10 \%)$ and $<57.4 \mathrm{mmol} / \mathrm{mol}(7.4 \%))$ and total cholesterol $(<5 \mathrm{mmol} / \mathrm{L})$ thresholds. Secondary outcomes were evidence of sustained learning and changes in the number of patients referred to secondary care.

Results: Evaluation of care processes and quality outcomes took place 15 months after the programme was initiated. The proportion of patients with a $\mathrm{HbA1c}$ of $<57.4 \mathrm{mmol} / \mathrm{mol}(7.4 \%)$ and $>85 \mathrm{mmol} / \mathrm{mol}(10 \%)$ was significantly higher (44\% vs $53 \% \mathrm{p}=0.0001$ ) and lower ( $12.5 \%$ vs $10 \% ; p=0.002)$ respectively. There was an increase in the proportion $(95 \% \mathrm{Cl})$ of patients receiving foot care reviews $(+26.0 \%(24.0 \%$ to $28.1 \%))$, microalbuminuria screening $(+29.8 \%(27.7 \%$ to $31.9 \%))$ and who achieved targets for blood pressure $(+9.6 \%$ $(7.5 \%$ to $11.6 \%))$ and total cholesterol $(+14.4 \%(12.3 \%$ to $16.5 \%) ; p<0.001) .241$ fewer patients were referred to secondary care. Increases in the healthcare professional's confidence and collaborative clinical behaviour were evident 3 years after completing the programme.

Conclusions: An experiential, interprofessional intervention can result in significant improvements in quality outcomes in association with a sustained impact on behaviours and practices.

\section{Strengths and limitations of this study}

- This is the first analysis of behavioural and clinical outcomes following an interprofessional education programme (IEP) for diabetes care in a community.

- There was an a priori evaluation of the change in the care pathway and referral practices which are key components of current service redesign programmes.

- Participants reassessed 3 years after IEP exposure showed sustained learning.

- Factors other than the IEP could have contributed to the behavioural changes which needs further evaluation in future studies.

\section{INTRODUCTION}

In the UK, diabetes mellitus affects 2.9 million adults and a further 850000 affected people are undiagnosed. ${ }^{12}$ Current expenditure on diabetes care accounts for $10 \%$ (£23.7 billion) of the total National Health Service (NHS) budget. ${ }^{3}{ }^{4}$ A drive towards delivering more 'patient-centric' care in the community is considered a more efficient way to manage this growing burden of disease. $^{5}{ }^{6}$ To achieve this though, nonspecialist practitioners will need to extend their scope of service provision.

Postgraduate practitioners have already achieved specific qualifying standards of knowledge and competencies, which define values, beliefs, attitudes, customs and scope of practice. ${ }^{78}$ Attempting to change these professional boundaries could contribute to fragmentation of care. $^{9}$ Evaluations of interprofessional education programmes (IEPs) are primarily limited to participant satisfaction. We evaluated an IEP that was specifically designed for non-specialists. The purpose of the programme was to systematically change 
practice behaviours in the locality and reduce the need for specialist input in the secondary care setting. From this historical data, we have assessed changes in clinical behaviours, challenges in practice and the impact on quality of care. We describe a novel form of IEP which could now contribute to the future design of modern diabetes services.

\section{METHODS}

The practices involved in this evaluation were set in a single locality with relatively high deprivation in an inner city borough in South London, UK. In 2005, we held face-to-face consultations with groups of general practitioners and practice nurses in order to identify the areas of diabetes care they considered challenging. Using the Likert scale-from 0 (no confidence) to 10 (fully competent)-practitioners were asked to document their confidence to manage or organise care for patients in the following areas: newly diagnosed diabetes, hypertension, microalbuminuria, renal disease, hypoglycaemia, neuropathy, foot care and cardiovascular disease. These data and the feedback from discussions about logistics were used to develop the curriculum and the programme itinerary, respectively.

The programme was made up of 10 weekly, $3 \mathrm{~h}$ sessions in classes with a 50:50 balance of places for general practitioners and practice nurses. The learning objectives were met with interactive lectures and workshops to which the participants could contribute their own case material. It was validated with a structured clinical assessment known as an Objective Patient Evaluation Review and Assessment (OPERA). The OPERA consisted of a circuit of supervised stations where the participant was given 6 min to complete a management task related to either a clinical scenario (presented by trained actors/patients) or the interpretation of data. Participants were sent written feedback of their performance in the OPERA and a certificate of attendance. Subsequently, a hospital specialist visited the practitioners in their own surgeries to observe their management of patients they had selected as being challenging. The programme was endorsed by the Royal College of General Practitioners in the UK.

\section{Quantitative data collection}

Data were extracted from the practices' diabetes registers to assess changes in the proportion of patients who received foot reviews, an assessment of urine albumin: creatinine ratio, and the measurement of blood pressure, glycated haemoglobin A1c (HbAlc) and total cholesterol before, and 15 months after the inception of the IEP. The thresholds for care quality outcomes in the templates used to extract data in 2004/2005 were for $\mathrm{HbAlc}>86 \mathrm{mmol} / \mathrm{mol}(10 \%)$ and $<57.4 \mathrm{mmol} / \mathrm{mol}$ (7.4\%), for blood pressure, $<145 / 80 \mathrm{~mm} \mathrm{Hg}$, and for total cholesterol $<5 \mathrm{mmol} / \mathrm{L}$. These thresholds were adopted for the Quality Outcome Framework (QOF) for diabetes and cardiovascular risk based on the best available evidence compiled by the National Institute of Clinical Excellence. ${ }^{10}$

The QOF score measures practice level achievements against a range of evidence-based indicators for diabetes. The practice-based data are available to the public in the UK government's Health and Social Care Information Centre (http://www.qof.ic.nhs.uk/) and are collected annually. Here, we report the average proportion (percentage) of the available points that were achieved by the collective group of 26 practices over three consecutive years after the IEP had been established for 12 months. The QOF data analysis provided and independent, and external evaluation of long-term trends in performance for these practices.

Over a 4-month period, the number of diabetes case referrals to secondary care was extracted from the hospital records before, the programme began and the exercise was repeated 1 year later.

Within-group comparisons were made by constructing contingency tables and performing either two-tailed $\chi^{2}$ or Fischer's exact tests (Graphpad Prism V.5.04, San Diego, USA). We present proportionate differences for categorical data. Measures of centrality are reported as mean and $95 \%$ CIs for continuous data.

A $p$ value of $<0.01$ was considered statistically significant.

\section{Qualitative data collection}

The aim was to evaluate the learning and clinical behaviours of non-specialist, multiprofessional teams in the community. We adopted a case study approach and a suite of evaluation tools including focus groups, questionnaires, interviews and observations. Interview questions were composed according to preidentified themes discovered through literature review. We assessed participants' clinical behaviours within the first year (shortterm) and after 3 years (long-term) of completing the programme.

\section{Focus groups}

Focus groups were held at the beginning and end of the first two, 10-week cycles of the IEP. Questions were loosely scripted in advance, to facilitate discussions which were limited to $20 \mathrm{~min}$. In the first round, we explored issues around individual motivation for coming on the course and expectations; how participants had found the organisation and structure of the course in the initial stages; some of the early impressions of how expectations were being fulfilled; and the experience of interprofessional or shared learning. At the end of the IEP, we revisited some of these issues as well as exploring in detail the extent to which learning from the course had been applied in practice. A short questionnaire relating to similar themes was administered at the end of the focus groups. 


\section{In-depth interviews}

Purposive sampling was used to select a group of four general practitioners and four practice nurses to take part in an in-depth interview at the beginning and at the end of one cycle. These interviews were semistructured allowing flexibility for participants and encouraging a greater depth of information to be articulated. An open question format was used to encourage a discourse and to allow additional questions to be formulated based on the responses.

In 2013, we interviewed participants who had completed the programme 3 years earlier. A sample of four general practitioners and four nurses contributed to this repeat analysis. The purpose of this set of interviews was to determine what, if any, changes in clinical behaviours documented earlier in the shorter term were evident in the longer-term.

\section{Observations}

Observations of the teaching sessions served to reinforce and illuminate themes arising from the focus groups, questionnaires and interviews, especially in relation to interprofessional communication and behaviour.

The IEP taught sessions were divided into a lecture followed by a workshop. Participants were randomly allocated to small groups in the workshop which changed each week. The evaluators (DF and EA) observed one group at random each week. Inter-relater reliability was established by using day 1 of a cycle as a pilot to test the observational categories and again on day 6 .

This multimethod approach to evaluation was chosen to provide rigour and enable us to compare and corroborate our findings. A framework analysis using the preidentified themes was performed on the interview data. After all transcripts had been printed, the first two transcripts were read multiple times to gain a preliminary observation and a comprehensive understanding of the data. Transcripts were coded iteratively. Any disagreement of coding between the researchers were identified, discussed and clarified. All identified quotes were then electronically cut and pasted on to a new document according to the themes. The final products were documents that contained quotes of the same theme. A short summary was written for each interview.

All interviewees provided written informed consent. The collection of data and interviews were anonymous.

\section{RESULTS}

\section{Quality of care}

In the first year, 57 practitioners (39\% practice nurses) received completion certificates. Over this period, the number of registered (prevalence of) patients with diabetes increased from $4167(2.9 \%)$ to $4593(3.2 \%)$. The proportions receiving foot care reviews, with blood pressure $<145 / 85 \mathrm{~mm} \mathrm{Hg}$, screened for microalbuminuria, and with a total cholesterol of $<5 \mathrm{mmol} / \mathrm{L}$ significantly increased. There was an improvement in overall diabetes control (figure 1). HbA1c was evaluable in $3187(77 \%)$ and $3757(82 \%)$ patients at baseline and follow-up, respectively. Compared with baseline measurements, the proportions of patients at follow-up with a HbAlc $>86 \mathrm{mmol} / \mathrm{mol}$ fell from $12.5 \%$ to $10 \% ; \mathrm{p}=0.002$, and $<57.4 \mathrm{mmol} / \mathrm{mol}$, increased from $43.8 \%$ to $53.1 \%$; $\mathrm{p}=0.0001$. The number of patients referred to secondary care fell by $241(-16 \% ; \mathrm{p}=0.001)$.

The management of 110 patients with type 2 diabetes (36\% female) with a mean age of 57.4 years and HbAlc of $77 \mathrm{mmol} / \mathrm{mol}(9.2 \%)$ was observed in the practices. The most common therapeutic decision in $59 \%$ of cases was to initiate or titrate oral hypoglycaemic agents (figure 2).

In 2005 , the practices that took part in the IEP programme earned a higher percentage of the QOF points for diabetes care compared with other practices in London which were not exposed to this programme
Figure 1 Changes in the percentages of diabetes process andQOF targets in 4167 patients before (blue bars), and 4593 patients (red bars) 15 months after 57 practitioners from 26 practices completed an IEP. BP, blood pressure; HbA1c, glycated haemoglobin; IEP, interprofessional education programme; QOF, Quality Outcome Framework.

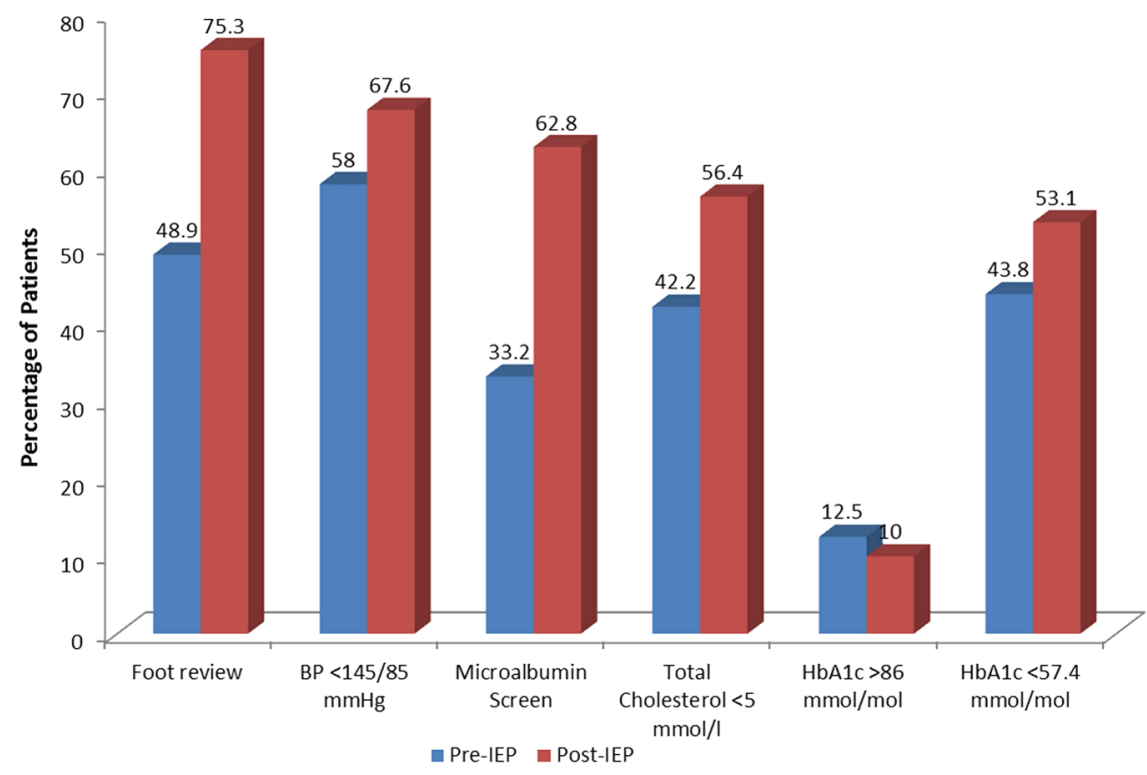


Figure 2 Therapeutic decision outcomes for the 110 cases observed in practice $(\mathrm{BP}$, blood pressure; $\mathrm{OHA}$, oral hypoglycaemic agent).

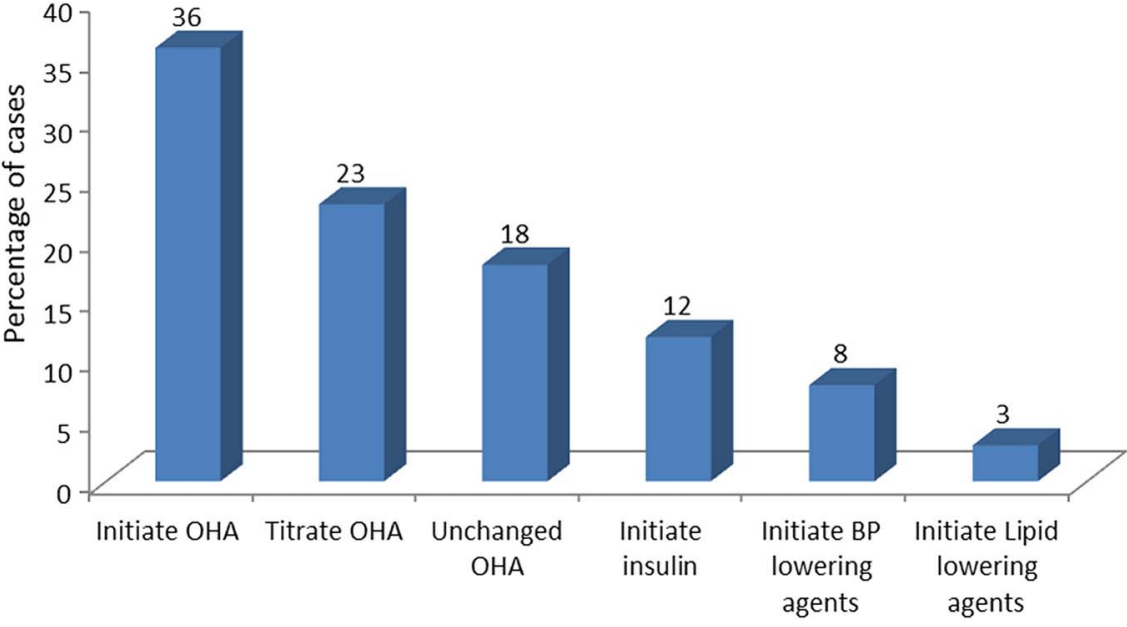

(94\% vs $89 \%$ ). The average percentage of the points for diabetes earned by the IEP practices progressively increased each year in the 3 years from 2006 to 2008 and were consistently higher than the group average of non-IEP practices $(96.8 \%$ vs $94.5 \%, 98.5 \%$ vs $95.3 \%$ and $99.0 \%$ vs $96.2 \%$, respectively).

\section{Qualitative assessment outcomes}

In our literature review, interprofessional education was seen as an important strategy for promoting greater collaboration between healthcare professionals. Greater collaboration was considered necessary to improve services and patient outcomes.

In general, the interviewees considered the programme to be novel and one in which they were keen to participate. The course was highly regarded for its practicality since most sessions were taught with the concept of learning-by-doing and based on realistic scenarios. All interviewees acknowledged that learning with different professions in the same classroom was beneficial to them.

The initial assessments showed that collaboration was perfunctory between primary and secondary care. Referral of patients to secondary care took place with little personal interaction between the community and specialist healthcare personnel. The design of this IEP provided a good opportunity for better communication between primary and secondary care. However, collaboration within practices was variable. The availability of time and resource to discuss and investigate cases was considered a barrier:

Of course, you know, the number of patients you are seeing in the morning, how much time you got for each patient, hugely impacts on how collaborative you can be... (participant 7)

The focus groups and interviews showed that participants appreciated the time to interact with specialists in the taught sessions and in their practices.

Having protected time, time put aside for consultants to be able to liaise with primary care, with the team in the community, just time where it is separate from their clinical duties... (participant 4)

There was evidence that the programme increased knowledge and promoted communication, collaboration and understanding of each other's roles.

Because it exposes us to the team, normally we see each other's names on paper, but we don't know who they are...teaching us in a team we get familiar with them, we feel more comfortable discussing any issues with them... (participant 10)

In the longer term assessments, 3 years after completing the programme there was evidence of changes in approach to diabetes care being implemented in practice. There was also evident learning according to Kirkpatricks and Barr's learner hierarchy ${ }^{11}$ in which participants noted that patients were benefiting from the changes (table 1).

\section{DISCUSSION}

The participants in this interprofessional programme became more confident and collaborative within their own practices and with secondary care in the short and longer terms. This translated into fewer referrals being made to secondary care from primary care and improvements in the quality of diabetes outcomes. This experiential approach to learning is well founded but not previously evaluated in this context. ${ }^{12}$ This method could underpin the change in behaviour required to modernise diabetes services today.

Interprofessional education with an acquisition of new skills and knowledge is highly rated. ${ }^{13}$ However, evaluations of the impact of IEPs for health professionals caring for patients with diabetes in the community in the UK do not exist. A recent study showed that a 3-day programme was associated with improvements in knowledge and collaboration but had no impact on performance of teams delivering diabetes care. ${ }^{14}$ Bailey et al demonstrated little change in nurse practitioner/family physician collaboration due to a perceived lack of 
Table 1 Themes and quotes from the follow-up interviews of participants in 2013 who completed the 2010 interprofessional education programme (IEP) cycle in relation to the four stages of Kirkpatrick and Barr's learning hierarchy which describe outcomes exclusive to interprofessional education

\begin{tabular}{|c|c|}
\hline Themes & Quotes \\
\hline 1-Reaction & $\begin{array}{l}\text { "I thought it [the OPERA] was excellent, it was very nerve racking...the actors played very } \\
\text { good parts...they weren't open with a lot of information, we needed to pick [search] for } \\
\text { that, we needed to find the basis of their problems which is true in diabetes care" } \\
\text { (participant 8) }\end{array}$ \\
\hline $\begin{array}{l}\text { 2a-Modification of attitudes/ } \\
\text { perceptions }\end{array}$ & $\begin{array}{l}\text { "Invariably you will end up talking about certain case-studies and putting your thoughts or } \\
\text { point of view forward from your professional perspective...that's really nice for everybody to } \\
\text { understand the issues a profession may have with that particular thing" (participant } 7 \text { ) }\end{array}$ \\
\hline $\begin{array}{l}2 \mathrm{~b} \text {-Acquisition of knowledge } \\
\text { and/or skills }\end{array}$ & $\begin{array}{l}\text { Since [the IEP] Ihave had newly diagnosed patients referred to me with off-the-scales } \\
\text { HBA1C, which I was being able to bring right down, which was very satisfying." } \\
\text { (participant } 7 \text { ) }\end{array}$ \\
\hline 3-Behavioural change & $\begin{array}{l}\text { "'After having more knowledge I really changed my practice enormously, as a result of } \\
\text { attending the course, I'm much more confident at looking at scenarios and changing } \\
\text { treatments... also getting the patient to focus more on themselves..." (participant } 3 \text { ) }\end{array}$ \\
\hline 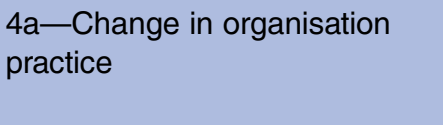 & $\begin{array}{l}\text { "...there were changes in prescribing, we are concentrating on making prescribing uniform } \\
\text { throughout the practice, changing to be more cost-effective... if combination therapy is } \\
\text { available and cheaper then we changed to them..." (participant } 6)\end{array}$ \\
\hline 4b-Benefits to patients/clients & $\begin{array}{l}\text { "They [the general practitioners] were referring more complex problems to us [practice } \\
\text { nurses], and they're dealing with the more mundane problems...they know what to do with } \\
\text { newly diagnosed...patients are being better managed in primary care for longer times and } \\
\text { targets are much better achieved now...this is really good for the patient" (participant } 1 \text { ) }\end{array}$ \\
\hline
\end{tabular}

appreciation of the knowledge bases possessed by the nurse practitioners. ${ }^{15}$ By contrast, we found a sophisticated understanding existed between these health professional groups of each other's role.

It is of interest that the practices that participated in this IEP consistently achieved the higher QOF scores compared with those that were not involved in the programme. These outcomes occurred before the establishment of payments for performance which some authors consider has had a questionable impact on improvements in the quality of care. ${ }^{16}$ Caution is required in interpreting this observation because adjustments were not made for potential confounding factors such as exception reporting, different levels of resourcing and demography between the participating and nonparticipating practices.

The rapid increase in the incidence of diabetes demands a radical change in service provision. Shifting care to the community can result in disassociation or fragmentation of care unless there are additional means to maintain integrity, quality and safety. Collaboration is a crucial currency to support integrated care models being recommended to cope with the disease burden. Short-term IEPs have not previously been evaluated for their long-term impact. ${ }^{17}$ A recent meta-analysis suggests that quality improvement strategies that only focus on healthcare professionals may be limited to improvements in those patients with very poor diabetes control. ${ }^{18}$ Our findings, however, have shown that a validated, educative intervention of this duration and depth can produce significant improvements in the quality of diabetes care across the spectrum of HbAlc measurements. Whereas broader quality improvement strategies can benefit patients with very poor control, the evidence for their ability to tighten control to achieve the best risk reductions is limited. ${ }^{19}$ It is of note, therefore, that our IEP intervention showed a significant improvement in the proportion of patients achieving diabetes control with $\mathrm{HbAlc}<57.4 \mathrm{mmol} / \mathrm{mol}$ and reducing the proportion with very poor control.

We conducted a practical formative assessment and observed learning in practice in the participants' own work environment. This combination of experiential teaching features are unique to this programme. The observed practice indicated that selection and use of new diabetes agents was challenging. This suggests that continuing experiential education for the non-specialist practitioner that focuses on the use of new therapies need to be addressed in future iterations of this programme.

Our mixed-method analysis suggests that sufficient exposure to an experiential IEP is a powerful way to deliver change in clinical behaviours that can impact the quality of diabetes care in a community. In the developed world, there is a desire to reform services in line with the challenges of a changing demography of ageing patients and workforce retention. Various models have been considered and implemented including pay-for-performance but rigorous assessment of their efficiency is lacking. ${ }^{20}$ Our evaluation is limited by the lack of a specific control group with alternative educational interventions. 
However, we report a 'step change' in diabetes outcome by several measures within the locality and in comparison to other practices. These findings are linked to changes in the attitudes of clinicians that we rigorously assessed and showed was consistent and persistent over the short and long term. We are not aware of any intervention programme that specifically and systematically addressed attitudes to diabetes care provision for a workforce of non-specialists in this way.

Educational interventions need to be progressive and evolve with the changing and varied educational needs of healthcare professionals. Our rolling programme design allowed us to remain engaged with the participant cohort before, during and after their involvement in the IEP. We could, therefore, adjust and update the curriculum as new information and evidence emerged. This will be particularly important in helping clinicians manage the plethora of new treatment combinations for diabetes.

Investment is required to maintain workforces in order to sustain good outcomes. In the future, prospective, controlled studies are required to understand the impact and efficacy of these interventions. Importantly, additional work is required to understand whether this, and other models are, or likely to be, of benefit to the health economy.

Acknowledgements The authors would like to thank Rosemary Kennedy who co-ordinated the education programme. Rosemary Kennedy received support from unrestricted educational grants from the Wandsworth Teaching PCT, Novo Nordisk and Takeda pharmaceutical.

Contributors DC, DF, EA and KE were involved in data collection and data interpretation. DC and KE were involved in writing the article. All authors reviewed and revised versions of the manuscript. KE is the guarantor of the work and takes responsibility for the integrity of the data.

Competing interests None declared.

Ethics approval Imperial College and the Research and Development Department of St George's University of London, UK.

Provenance and peer review Not commissioned; externally peer reviewed.

Data sharing statement No additional data are available.

Open Access This is an Open Access article distributed in accordance with the Creative Commons Attribution Non Commercial (CC BY-NC 4.0) license, which permits others to distribute, remix, adapt, build upon this work noncommercially, and license their derivative works on different terms, provided the original work is properly cited and the use is non-commercial. See: http:// creativecommons.org/licenses/by-nc/4.0/

\section{REFERENCES}

1. Diabetes UK. Diabetes in the UK 2012: Key statistics on diabetes. 2012. https://www.diabetes.org.uk/Documents/Reports/Diabetes-inthe-UK-2012.pdf

2. Diabetes Health Intelligence. APHO Diabetes Prevalence Model. Yorkshire \& Humber Public Health Observatory. 2012 [10 September 2012]. http://www.yhpho.org.uk/resource/view.aspx? $\mathrm{RID}=81090$

3. Department of Health. Spending Review. Department of Health. 2010 [15 November 2012]. http://webarchive.nationalarchives.gov.uk/ +/www.dh.gov.uk/en/MediaCentre/Pressreleases/DH_120676

4. Hex N, Bartlett $C$, Wright $D$, et al. Estimating the current and future costs of Type 1 and Type 2 diabetes in the UK, including direct health costs and indirect societal and productivity costs. Diabet Med 2012;29:855-62.

5. NHS London Health Programmes. Diabetes Guide for London. 2011 [20 September 2012]. http://www.Iondonhp.nhs.uk/wp-content/ uploads/.../Diabetes-Guide.pdf

6. Department of Health. The health and care system in April 2013 [infographic]. Department of Health, 2012 [1 February 2013]. http:// healthandcare.dh.gov.uk/the-health-and-care-system-in-april-2013infographic/

7. Hall P. Interprofessional teamwork: professioanal culture as barriers. $J$ Interprof Care 2005;19(Supplement 1):188-96.

8. Amour DD, Oandasan I. Interprofessionality as the field of interprofessional practice and interprofessional education: an emerging concept. J Interprof Care 2005;19(Supplement 1):8-20.

9. Hilton RW. Fragmentation within interprofessional work. A result of isolationism in health care professional education programmes and the preparation function only in the disciplines of students to confines of their own disciplines. J Interprof Care 1995;9:33-40.

10. Mclntosh A, Hutchinson A, Home PD, et al. Clinical guidelines and evidence review for Type 2 diabetes: management of blood glucose. Sheffield: ScHARR, University of Sheffield, 2001.

11. Freeth D, Reeves S, Koppel I, et al. Evaluating interprofesisonal education: a self help guide 2005.

12. Gillan C, Lovrics E, Halpern E, et al. The evaluation of learner outcome in interprofessional continuing education: a literature review and an analysis of survey instruments. Med Teach 2011;33:e461-70.

13. Kolb AY, Kolb DA. Learning styles and learning spaces: enhancing experiential learning in higher education. Acad Manage Learn Educ 2005;4:193-212.

14. Barr H, Freeth D, Hammick M, et al. Evaluations of interprofessional education. UK, 2000. http://caipe.org.uk/silo/files/evaluations-ofinterprofessional-education.pdf

15. Yamani N, Asgarimoqadam M, Haghani F, et al. The effect of interprofessional education on interprofessional performance and diabetes care knowledge of health care teams at the level one of health service providing. Adv Biomed Res 2014;3:153.

16. Bailey $P$, Jones $L$, Way $D$. Family physician/nurse practitioner: stories of collaboration. J Adv Nurs 2006;53:381-91.

17. Calvert M, Shankar A, McManus RJ, et al. Effect of the quality and outcomes framework on diabetes care in the United Kingdom: retrospective cohort study. BMJ 2009;338:b1870.

18. Tricco AC, Ivers NM, Grimshaw JM, et al. Effectiveness of quality improvement strategies on the management of diabetes: a systematic review and meta-analysis. Lancet 2012;379:2252-61.

19. Reeves S, Perrier L, Goldman J, et al. Interprofessional education: effect on professional practice and healthcare outcomes (update). Cochrane Database Syst Rev 2013;3:CD002213.

20. Schofield D, Cunich MM, Naccarella L. An evaluation of the quality of evidence underpinning diabetes management models: a review of the literature. Aust Health Rev 2014;38:495-505. 